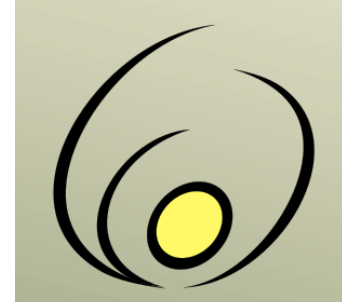

Fórum de Pró-Reitores de Extensão das Instituições Públicas de

Educação Superior Brasileiras

\section{Revista Brasileira de Extensão Universitária}

v. 11 , n. 2 , p. $135-144$, mai.-ago. 2020

e-ISSN 2358-0399

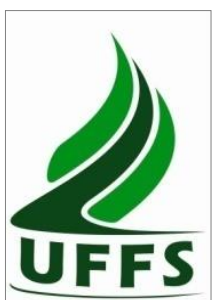

Content shared under Creative Commons Attribution 4.0 Licence CC-BY

\title{
A pessoa do professor: significados e sentidos sobre uma experiência formativa
}

\author{
Giovana Maria Belém Ferreira Falcão ${ }^{1}$, Afrânio Vieira Ferreira ${ }^{2}$
}

Resumo: Os processos formativos destinados aos professores não podem se orientar somente numa perspectiva técnica, distante das vivências e experiências da escola, sem levar em conta a natureza subjetiva que há no trabalho docente. Este escrito, tem por objetivo compreender como os professores participantes do projeto de extensão "Olhar para mim, para olhar para o outro: a dimensão subjetiva da formação docente", significaram a formação vivenciada. O projeto aconteceu no ano de 2017 e envolveu professores da Educação Básica do Município de Iguatu-CE e alunos do curso de Pedagogia de uma universidade pública. Como os docentes significaram a participação nessa experiência formativa? Para responder a indagação, ouviu-se nove participantes, por intermédio de questionário, tendo, também, consultado registros de áudio e escritos realizados ao longo do projeto. A investigação, de natureza qualitativa, do tipo exploratória, se apoia, principalmente, nos estudos de Vygotsky, Nóvoa e Cunha. O estudo revelou que a formação se constituiu relevante experiência formativa para todos os envolvidos, manifestando-se como espaço de expressão sobre os desafios vivenciados no exercício da profissão, a partilha de experiências, o reconhecimento e a renovação dos saberes docentes, contribuindo no fortalecimento da identidade docente e no desenvolvimento de profissionais mais autônomos, críticos, bem como numa atuação docente mais ativa e efetivas.

Palavras-chave: Formação de professores; Identidade; Trabalho docente

\section{The teacher as a person: meanings and senses within a formative experience}

Abstract: Formative processes for teachers cannot be merely focused on a technical perspective, distant from school experiences and without considering the subjective nature of the teaching work. This study aims at understanding how teachers who participated in the extension project entitled "Looking at myself to look at the other one: the subjective dimension of teacher education" processed the training experience. The project took place in 2017 and involved Basic Education teachers from the Iguatu municipality (Ceará State, Brazil), as well as Pedagogy students from a public university. How did teachers understand their participation in this formative experience? In order to answer this question, we heard nine participants based on a questionnaire. Audio recordings and essays produced during the project were also analyzed. It was a qualitative, exploratory research based mainly on Vygotsky, Nóvoa and Cunha theories. The study revealed that the formative process became an important formative experience for all the involved. Resulting in a space of expression about the experienced challenges during the exercise of their profession, to share experiences, the recognition and the renovation of the teacher's knowledge, thus contributing on the strengthening of the teacher's identity as well as the development of more independent and critical professionals, acting in a more active and effective way as teachers.

Keywords: Teacher Training; Identity; Teacher Work
Originais recebidos em

29 de abril de 2019

Aceito para publicação em

08 de maio de 2020

1

Psicóloga. Doutora e Mestre em Educação. Professora Assistente da Universidade Estadual do Ceará UECE e do Programa de PósGraduação em Educação da UECE.

giovana.falcao@uece.br

(autora para correspondência)

2

Pedagogo. Professor da Educação Básica. 


\section{Introdução}

Pensar na escola e no trabalho docente exige entender o contexto histórico, cultural e social, conforme nos ensina Vygotsky (2009). Com efeito, é preciso compreender que a sociedade atual se caracteriza por mudanças nas mais diversas áreas, sendo que estas, certamente, irão reverberar diretamente no trabalho do professor e em sua pessoa, uma vez que constituímos nossa subjetividade na relação com a realidade na qual estamos inseridos.

Os avanços nas áreas da ciência e da tecnologia e as novas maneiras de se produzir exigem que as instituições de ensino preparem os estudantes para lidar com as inovações surgentes e com os desafios desses novos tempos. Fernandes (2000) salienta que a pressão para a mudança origina outras concepções de educação e de formação de professores, alterando o conceito de escola.

Sendo assim, a Educação e a formação docente são entendidas como áreas estratégicas na promoção do desenvolvimento social de um mundo globalizado. De acordo com Silva (2007), entretanto, a centralidade conferida aos professores e à sua formação no contexto das políticas educacionais implantadas nos últimos anos ocorre mais para atestar a expansão no que concerne à quantidade de políticas de formação de professores do que de valorização do seu pensamento, do seu sentir e de seus valores como aspectos importantes para se compreender os desafios de seu trabalho e, por conseguinte, para investir em condições que favoreçam sua melhoria e a qualidade do ensino.

Nesta mesma perspectiva, Gatti (2008) procede a importantes reflexões para entendermos o destaque recorrentemente conferido à formação docente, considerando que o tema é movido por uma série de interesses não só nacionais, como também por movimentos internacionais, conforme expressa:

$\mathrm{Na}$ última década, a preocupação com a formação de professores entrou na pauta mundial pela conjunção de dois movimentos: de um lado, pelas pressões do mundo do trabalho, que se vem estruturando em novas condições, num modelo informatizado e com o valor adquirido pelo conhecimento, de outro, com a constatação, pelos sistemas de governo, da extensão assumida pelos precários desempenhos escolares de grandes parcelas da população (Gatti, 2008, p. 60).

Embora haja o reconhecimento da necessidade de investir em formação de professores, ainda predomina uma preparação que privilegia conteúdos teóricos e técnicos, pouco se investindo em uma formação que favoreça o desenvolvimento em seu sentido mais amplo. A busca por mais conhecimento é uma necessidade inegável, no entanto, é preciso muito mais que o saber teórico. Nóvoa (1995) defende o argumento de que a formação docente vai além do aprendizado de metodologias e de aquisição de conhecimentos. Ela está relacionada ao crescimento e ao aperfeiçoamento dos professores como profissionais, exprimindo-se como aspecto de considerável relevo na constituição da identidade do professor. Assim, o processo formativo significa investimento pessoal, trabalho sobre os percursos e os projetos próprios, direcionando a visão para os professores e pessoas que há imersos nesses profissionais.

Desse modo, os processos formativos destinados aos professores não podem se orientar somente numa perspectiva técnica, distante das vivências e experiências da escola, sem creditar a natureza subjetiva que há no trabalho docente. Faz-se mister que a formação de professores privilegie o ser humano em todos os seus aspectos, incluindo os de cunho subjetivo inerentes a ele. É preciso, pois, pensar em uma formação docente mais realista, atenta as necessidades dos sujeitos, que demande conhecer o professor em sua individualidade, considere os contextos onde ele é inserto, possibilitando assim, o seu desenvolvimento de modo integral. Afinal, nos constituímos na interação com a história, com a cultura, nas interações sociais, como salienta Vygotsky (1994). 
Intentando desenvolver uma formação habilitada a favorecer desenvolvimento de aspectos subjetivos da profissão, como o maior conhecimento de si e o fortalecimento da identidade docente - e que atente para o professor em seus diversos aspectos - propusemos, no início do ano de 2017, o Projeto de Extensão intitulado: 'Olhar para mim para olhar para o outro: a dimensão subjetiva da Formação docente'. A proposta envolveu alunos do curso de licenciatura em Pedagogia da Faculdade de Educação, Ciências e Letras de Iguatu (FECLI), componente da Universidade Estadual do Ceará (UECE) e professores da Educação Básica desse Município cearense.

As atividades foram desenvolvidas durante todo o ano de 2017, envolvendo professores em formação (graduandos do curso de Pedagogia) e docentes já em exercício (professores da Educação Básica). Dentre as ações formativas, realizamos estudos teóricos, vivências na escola, participação em eventos científicos com defesa de trabalhos desse gênero. Com efeito, o projeto se propôs atingir a formação inicial de licenciandos e a formação continuada de professores da Educação Básica.

De que modo os professores significaram a participação nessa experiência formativa? As atividades conseguiram favorecer mudanças em seus processos subjetivos, como a maior consciência de si e de suas identidades? Trouxeram implicações em suas práticas docentes?

Animado por essas indagações, este escrito, de modo particular, tem por objetivo compreender como os professores participantes significaram a formação vivenciada nos encontros propostos pelo projeto extensão 'Olhar para mim para olhar para o outro: a dimensão subjetiva da Formação docente'. O interesse, portanto, repousa em entender como as vivências do mencionado projeto de extensão reverberaram na pessoa do professor, em suas subjetividades. Importa esclarecer que, ao evidenciarmos a expressão pessoa do professor, aludimos às ideações do educador português Antônio Nóvoa (2009, p.06), quando este defende que "o professor é a pessoa, e que a pessoa é o professor". De tal sorte, não se pode separar as dimensões pessoais e profissionais. O autor faz referência, portanto, à subjetividade do docente, aspecto que intentamos desvelar neste escrito.

As ações do projeto foram vivenciadas com o grupo de professores, nos meses de junho a dezembro do ano de 2017. Os participantes atuam no Ensino Fundamental II em escola da rede municipal de Iguatu-CE.

Ao fazer remissão aos significados e sentidos, tomamos como referência o trabalho de Vygotsky (2009). De acordo com o celebrado autor bielo-russo, significado é, pois, a estabilização de ideias por um determinado grupo. Estas ideias são utilizadas na constituição do sentido, que é de natureza individual. Na inteligência de L. S. Vygotsky,

[...] o sentido de uma palavra é a soma de todos os eventos psicológicos que a palavra desperta em nossa consciência. É um todo complexo, fluido dinâmico, que tem várias zonas de estabilidade desigual. O significado é apenas uma das zonas de sentido, a mais estável e precisa (p. 125).

Significado e sentido são distintos, porém, constituem par dialético, sendo interdependentes, um constitui o outro. Para Vygotsky (2009), enquanto os significados são construções sócio-históricas, as quais o indivíduo já encontra prontas e elaboradas historicamente, os sentidos são construções subjetivas, particulares e, portanto, em permanente construção.

Na sequência, discorremos sobre o caminho metodológico percorrido na consecução dos objetivos propostos - o projeto de extensão que deu origem ao escrito - e, sequentemente, trazemos as falas dos professores relativos à formação vivenciada. No módulo de remate do ensaio, tecemos algumas considerações complementares, a fim de conceder clareza integral às reflexões ora esboçadas. 


\section{Procedimentos metodológicos}

O estudo sob relatório se caracteriza por ser de natureza qualitativa. De acordo com Minayo (2001, p. 22) a pesquisa qualitativa: "[...] trabalha com o universo de significados, motivos, aspirações, crenças, valores e atitudes, o que corresponde a um espaço mais profundo das relações, dos processos e dos fenômenos que não podem ser reduzidos à operacionalização de variáveis". Desvelar significações exige considerar a subjetividade componente dos discursos, ideia que não pode ser quantificada, motivo pelo qual a busca, para chegar ao seu intento, há de eleger o aspecto da qualidade.

A investigação também se caracteriza por ser exploratória, uma vez que tencionamos ampliar o entendimento referente à formação desenvolvida com os participantes. Quem explica com amplo domínio conceitual esse tipo de demanda científica é Antônio Carlos Gil (2008), para quem

As pesquisas exploratórias têm como principal finalidade desenvolver, esclarecer e modificar conceitos e ideias, tendo em vista a formulação de problemas mais precisos ou hipóteses pesquisáveis para estudos posteriores. De todos os tipos de pesquisa, estas são as que apresentam menor rigidez no planejamento. (p. 27).

As falas dos professores sobre como significam a formação vivenciada no projeto de extensão, foram produzidas por via de um questionário, com questões abertas, respondidas por nove sujeitos. Para garantir o anonimato, os respondentes não se identificaram e são aqui referidos como participantes P1, P2 ... P9. Além do mencionado instrumento, consideramos os registros feitos por intermédio de áudios e anotações efetivadas no decorrer das ações na escola. As respostas foram coletadas no último dia de vivência do projeto na escola, que aconteceu no mês de dezembro de 2017. Os professores autorizaram a gravação em áudio, bem como o emprego dos indicadores recolhidos.

Apreender significados e sentidos é tarefa complexa, necessitando de que o pesquisador vá além da aparência e avance na apreensão dos modos de pensar, sentir e agir. Na perspectiva de Aguiar (2006, p.17),

[...] a apreensão dos sentidos não significa apreender uma resposta única, coerente, absolutamente definida, completa, mas expressões do sujeito muitas vezes contraditórias, parciais, que nos apresentam indicadores das formas de ser do sujeito, de processos vividos por ele.

Assim, procuramos analisar as falas dos participantes, indo além do que estava na aparência, com amparo num olhar e escuta sensíveis, com o objetivo de apreender a essência, entendendo que a palavra é sempre emocionada, como assinala Vigotsky (2009).

Para melhor alcançar o modo como realizamos a investigação, mostramos, sucintamente, o projeto de extensão 'Olhar para mim para olhar para o outro: a dimensão subjetiva da Formação docente'.

\section{O projeto de extensão: pesquisa e formação}

O projeto de extensão há pouco intitulado teve por objetivo desenvolver atividades formativas, envolvendo professores da Educação Básica do Município de Iguatu e alunos do curso de Pedagogia da FECLI/UECE, favorecendo o desenvolvimento de aspectos subjetivos da profissão como a maior consciência de si e de sua identidade. Também objetivávamos, de modo mais específico, possibilitar espaço de expressão para os professores acerca dos desafios vivenciados no cotidiano da escola, por intermédio de atividades vivenciais, reflexões e discussões; fortalecer a identidade docente de alunos e professores participantes do projeto, com esteio em reflexão sobre o fazer docente; favorecer a troca de experiências entre professores, possibilitando o reconhecimento e ampliação de seus saberes. 
A ideia do projeto foi contemplar alunos em formação e professores já em atuação, envolvendo a formação docente inicial e continuada, que, como bem se sabe, denota fragilidades. Para tanto, a equipe do projeto foi composta por uma professora do colegiado do curso de Licenciatura em Pedagogia da FECLI/UECE, na Sede da cidade de Iguatu e por graduandos do curso, sendo esses do $4^{\circ}$ e $6^{\circ}$ semestre pinçados por meio de seleção.

A proposta principal consistiu em ações vivenciais com alunos e docentes, que aconteceram em grupo, desenvolvidas em uma escola municipal. Antes de propor as atividades formativas, procuramos conhecer os professores e conversar sobre suas realidades e necessidades, com fito de planejarmos uma proposta formativa. Além das atividades formativas, avaliadas e planejadas a cada encontro, a equipe também realizou estudos teóricos sobre formação docente, desenvolvimento profissional e história de vida. Somadas as ações na escola, participamos de elaboração e apresentação de trabalhos em eventos na área de Educação e Semana Universitária, bem como ministramos oficina sobre história de vida em um evento promovido pela Universidade, à qual a equipe está vinculada.

A escola participante se localiza próximo ao campus da universidade proponente e atende Ensino Fundamental e Educação de Jovens e Adultos (EJA), modalidades de ensino levadas a efeito por profissionais da Pedagogia. Possui 32 professores, sendo 27 efetivos e 5 substitutos e atende a um público de cerca de 549 alunos matriculados entre o $1^{\circ}$ e $9^{\circ}$ anos nos turnos manhã e tarde, ao passo que, à noite funciona a EJA. Em média, participaram dos encontros formativos propostos 15 professores da escola.

Quinzenalmente, realizávamos encontros com os bolsistas para estudos teóricos sobre formação docente, ocasiões nas quais também fazíamos o planejamento e avaliação das atividades a serem procedidas na escola. Efetivaram-se seis encontros formativos ocorridos nos meses de junho, agosto, setembro, outubro, novembro e dezembro com os professores da escola, coordenadores e gestores, além de um encontro avaliativo final com os participantes da escola. Em cada encontro, elaborávamos relatório parcial e avaliávamos o encontro, para planejarmos as ações sequentes.

Encerramos as ações do projeto em janeiro de 2018, convindo ressaltar, por oportuno o momento, que todas as ações foram registradas em relatórios e gravações de áudio e fotografias, mediante autorização de todos os participantes.

No seguimento, estão reproduzidos os relatos dos professores sobre o que significou para eles a formação.

\section{Resultados alcançados: o que dizem os professores sobre a formação}

Desde os anos 1990, a formação de professores é merecedora de atenção de vários estudiosos, dentre os quais destacamos, com seus trabalhos, Nóvoa (1995, 2009), Imbernón (1999) e Gatti (2008). Estes autores são unânimes em apontar a necessidade de se pensar numa formação docente que não se restrinja a concepções teóricas e técnicas, mas que visem o professor em seus diversos aspectos. Além disso, destacam a relevância de ouvir os professores, entendendo que suas falas pouco são consideradas em muitos processos formativos.

$\mathrm{Na}$ avaliação realizada pelos professores, estes destacam diversos pontos que julgaram relevantes na formação. Também apontaram alguns limites vivenciados na experiência. Para melhor organizar os discursos, elencamos os sentidos atribuídos à formação em categorias, sendo estas a saber: falar de si; interações com o grupo; repercussão na prática docente; fortalecimento da identidade docente.

\section{Falar de si}


No decurso das ações formativas vivenciadas no projeto, procuramos desenvolver atividades no âmbito das quais os professores pudessem falar de si, de suas histórias de vida e trajetórias formativas. Para os participantes, comentar acerca de suas vidas constituiu relevante atividade, havendo eles destacado o fato de que esses momentos eram muito raros em suas rotinas. Nas avaliações, evidenciaram que foi muito bom relembrar fatos de suas vidas, de suas adolescências, e como esses eventos os foram conduzindo a serem quem são hoje. Um dos participantes afirmou: "Foi ótimo falar de mim, lembrar da minha adolescência e ver que o que eu sou hoje começou lá atrás" (P 5). De acordo com Cunha (1997), a narrativa de si tem o propósito de fazer a pessoa se tornar visível para ela própria.

No primeiro encontro com os professores, pedimos que se apresentassem a partir de imagens. Os participantes deveriam escolher gravuras com as quais se identificassem mais, bem como poderiam explicar o motivo da escolha. Esta foi uma atividade rica e de muita emoção, pois compartilharam importantes passagens de suas vidas, não somente sob o prisma profissional, mas também indicativas de aspectos relativos ao âmbito pessoal. Para alguns, no entanto, não foi tão fácil falar de si. Um dos professores contou "é difícil falar da gente, não costumo parar prá pensar em mim, mas foi bom, ajudou a botar prá fora" (P 01). A narrativa dele expressa que nem sempre é fácil falar de si ao mesmo tempo em que reconhece a importância de tal ato. De acordo com Falcão e Farias (2018):

Falar de si é algo complexo, porquanto exige humildade, criticidade e coragem, se constituindo em um custoso exercício. No entanto, favorece desenvolvimento da consciência de si, possibilitando reconhecer-se de modo realista, ao mesmo tempo, em que nos permite traçar perspectivas (p. 168).

Em um outro encontro, trabalhamos com história de vida, com suporte na música. Os participantes expressaram, com emoção, aspectos de suas histórias de vida, lembrando de pessoas ou situações que influenciaram na escolha pela docência, sendo muitos desses pontos ligados a aspectos familiares e experiências vividas ainda nos primeiros anos de existência. Foram destacados temas como amizade, amor, relacionamentos passados, relação com os pais em casa, professores que marcaram suas vidas etc. Um professor disse: "ouvir os colegas foi muito bom, ajudou a entender melhor as atitudes de cada um". (P 6). O grupo pôde fazer a relação das falas com a constituição de sua identidade docente, exercitou uma escuta respeitosa e ampliou o sentimento de empatia junto aos demais.

As falas dos participantes indicam que contar sobre suas histórias de vida permitiu aos professores revisitar seus passados, olhar para o presente e pensar em perspectivas. Cunha $(1997$, p. 2) defende que o ponto de vista conforme o qual, na oportunidade em que: "Quando uma pessoa relata os fatos vividos por ela mesma, percebe-se que reconstrói a trajetória percorrida dando-Ihe novos significados".

Além da importância para a formação docente, a história de vida se exprime como possibilidade metodológica, especialmente para a pesquisa qualitativa. Segundo Cunha (1997): "a produção de narrativas serve, ao mesmo tempo, como procedimento de pesquisa e como alternativa de formação" (p. 3). Para nós, esta experiência com a história de vida proporcionou a efetivação de ambas as atividades, haja vista que, no mesmo passo em que desenvolvíamos os momentos formativos, também realizávamos uma atividade de pesquisa.

\section{Interações com o grupo}

Outro aspecto destacado pelos professores diz respeito as interações dos participantes, porque, de acordo com eles, as atividades desenvolvidas permitiram que os docentes se conhecessem mais e partilhassem situações de seus cotidianos na escola. A fala de P2 confirma essa afirmação: "Os encontros foram muito bons. Os temas abordados, a socialização entre todos, tudo isso é muito importante para nosso dia a dia na sala de 
aula". Com esteio nesses relatos, é lícito inferir que os participantes reconhecem a importância das relações interpessoais para a prática docente. Nesta perspectiva Nóvoa (2009) defende o argumento de que a docência exige, cada vez mais, que se trabalhe em equipe e que se valorize o exercício coletivo da profissão.

Ainda no que é pertinente à relação dos participantes e como aprenderam com os colegas, P6 comentou: "O grupo interagiu muito bem, aprendemos uns com os outros e trocamos experiências, o que nos ajuda como professores". Para este, as atividades favoreceram a partilha de conhecimentos e a colaboração. Em outros momentos, alguns docentes comentaram que, por vezes, se achavam isolados, sem compartilhar com os colegas os problemas de suas salas. O desenvolvimento de uma cultura colaborativa entre os professores é aspecto que precisa ser fortalecido. Na perspectiva de Hargreaves (1998), a cultura colaborativa promove permanente transformação nos exercícios educativos, pois possibilita a troca de ideias, repensar a prática docente e o desenvolvimento da criticidade. Sendo assim, é preciso favorecer modalidades de relacionamento, no âmbito das quais a colaboração possa acontecer.

Segundo os professores relataram, os momentos de escuta entre eles foram muito ricos. Além de conhecerem mais uns aos outros, puderam ouvir como os colegas agiriam em algumas situações-problemas na sala de aula. Em um dos momentos vivenciados na formação, os professores deveriam eleger um caso para compartilhar com o grupo e pensar em alternativas. Ao escolher a situação para compartilhar, alguns dos docentes deram ênfase a momentos de conflitos vivenciados em sala de aula, fazendo uma reflexão sobre a relevância daquela passagem para sua constituição como professor. Enquanto um falava, os demais ouviam atentamente e exibiam seus pontos de vista acerca do relatado. Sendo assim, a atividade permitiu conhecer a realidade dos professores, possibilitando que falassem de situações concretas, o que favoreceu processos de reflexão, empatia e compreensão daquilo que foi compartilhado com os demais. Essa visão é corroborada pelo pensamento de Nóvoa (2009), quando o autor assinala que a formação de professores deve estar pautada nos estudos de casos cotidianos vivenciados no trabalho escolar.

\section{Repercussão na prática docente}

Ao expressarem sobre como a formação tinha repercutido em suas práticas docentes, os participantes ressaltaram que se conhecer mais, conhecer os colegas e pensar em problemas de suas salas de aula junto a seus pares foram ações de muita importância para pensarem sobre suas atuações em sala de aula e procurarem melhorar.

Um dos professores destacou: "As dinâmicas utilizadas nos encontros foram muito ricas, nos ajudaram a nos conhecer mais, foi muito bom "desabafar" e entender que podemos melhorar sempre. Também pudemos trocar experiências e aprender com os colegas" (P8). A fala do participante, nos transporta a refletir na relevância da reflexão para o desenvolvimento de uma prática docente efetiva, que considere a realidade do contexto, do professor e do aluno. Ouvir o outro e refletir sobre suas ações, coletivamente, decerto, são atos que favorecem mudanças na prática docente e possibilitam um fortalecimento da identidade do professor.

O debate sobre a formação docente, da inicial até a de ordem continuada, exprime, com muita frequência, o distanciamento teoria-prática, elementos que não podem ser pensados de modo dissociado. Talvez, ainda hoje, este seja o principal ponto de debate dentro dos cursos de licenciatura, sempre dando ensejo a polêmicas e transportando novos elementos a serem considerados como relevantes. Quando se reporta à formação continuada, essa dicotomia se faz, muitas vezes, evidente, haja vista que os conhecimentos repassados em diversificadas formações remetem a algo que aumenta ainda mais essa lacuna. Os docentes participantes assinalaram que os momentos formativos ofertados pela gestão municipal, na maioria das vezes, não consideram a realidade das escolas e das salas de aula, aportam metodologias tradicionais, pouco despertando o interesse em participar. As afirmações anteriores comungam com o pensamento de Gatti $(2008$, p. 59), 
quando ela assevera que estas formações "São projetos elaborados sob a coordenação do poder público, dentro de especificidades bem definidas".

Entrementes, no pensar de Nóvoa (2009), a formação de professores tem que ocorrer por dentro da profissão, onde os professores possam ter espaço de fala e escuta. Nas suas palavras, a defesa desse argumento se sustenta na afirmação de que deve existir "[...] uma formação de professores construída dentro da profissão". (P. 2). Ao considerarmos na devida conta a maneira como as atividades do projeto foram desenvolvidas e o pensamento de António Nóvoa, é possível garantir que as ações vivenciadas permitiram que os docentes fossem ativos dentro de seu processo formativo e não apenas expectadores, ouvintes ou agentes passivos, apenas recebendo e depositando informações, como na conhecida ideia paulofreireana de educação bancária.

Ainda nos reportando à importância da participação ativa dos professores nas formações continuadas, não podemos deixar de citar as ideias de Imbernón (2010). Para ele o que se faz é tentar resolver os problemas circundantes da escola de fora para dentro, convidando quase sempre alguém que não conhece a realidade para tratar das questões e problemáticas do local, além do estímulo à reprodução daquilo que é repassado. $O$ autor defende que é preciso buscar alternativas dentro da própria instituição, o que pode resultar em soluções, novas ideias para a prática docente ou qualquer outra demanda. Ainda é comum, entretanto, o fato de que as formações são ministradas por pessoas que pouco conhecem a instituição de ensino, sem ouvir os principais interessados, os professores, configurando, assim, como algo imposto, sem diálogo com quem vive aquela realidade.

\section{Fortalecimento da Identidade docente}

A identidade de professores não é um processo estático, mas configura algo que vai se constituindo no decorrer das interações e experiências. Pimenta e Anastasiou (2002) assim definem a identidade docente:

A identidade profissional constrói-se pelo significado que cada professor, enquanto ator e autor, confere à atividade docente no seu cotidiano, com base em seus valores, em seu modo de situar-se no mundo, em sua história de vida, em suas representações, em seus saberes, em suas angústias e anseios, no sentido que tem em sua vida o ser professor (P. 77).

Gatti (1996) lembra que a identidade precisa ser considerada nos processos formativos. Ainda de acordo com a autora, a identidade define um modo de ser no mundo, num dado momento, numa dada cultura, numa história, afetando o professor em suas perspectivas em relação à formação e suas modalidades de atuação profissional.

Os aspectos anteriores trazem, de modo implícito ou explícito, a ideia de que participar das atividades formativas promovidas pelo projeto de extensão 'Olhar para mim para olhar para o outro: a dimensão subjetiva da Formação docente', favoreceu o fortalecimento de suas identidades, à medida que permitiu se reconhecer no trabalho do colega, compartilhar experiências como professores, identificar e valorizar características como docente.

Ao expressar que "Foi muito interessante ouvir os colegas falando de suas histórias, a gente passou a se conhecer mais" (P9), o participante sinaliza a ideia de que está se constituindo sempre. Outro participante afirma que foi muito bom "entender que podemos melhorar sempre" (P8). Ao pensar sobre si e seu trabalho, os professores puderam refletir sobre novos modos de ser docente, o que, certamente, fortalece sua identidade.

Os professores destacaram, como aspecto negativo da formação, o pouco tempo que tiveram para participar dos encontros, pois estavam com muitas atividades na escola. Vejamos o que nos diz P3: "O que não foi muito bom, é que nem todos os colegas participaram, seria muito bom se todos tivessem participado e se tivéssemos 
tido mais tempo para os encontros". Em seus relatos fica explícita a intenção de que há necessidades de se despender mais tempo para os momentos formativos.

Os aspectos aqui discutidos evidenciam que a experiência formativa trouxe possibilidades de interação, reflexão, partilha de experiência, constituindo-se em considerável exercício formativo para os envolvidos, embora o tempo destinado aos encontros tenha sido restrito.

\section{Considerações finais}

De acordo com o relato dos participantes, a formação vivenciada a partir do projeto de extensão examinado favoreceu que os envolvidos ampliassem a consciência sobre suas atuações como docentes, refletissem sobre novas formas de atuar na docência, que contextualizassem melhor as problemáticas vivenciadas em seu cotidiano, o que, convictamente, vai reverberar no desenvolvimento de profissionais mais autônomos e críticos, bem assim numa atuação docente mais ativa e efetiva.

Com efeito, é válido acentuar que o projeto constituiu importante experiência formativa para todos os envolvidos, evidenciando-se como espaço de expressão sobre os desafios vivenciados no exercício da profissão, a partilha de experiências, o reconhecimento e a renovação dos saberes docentes.

Para nós, integrantes da equipe do projeto, a experiência possibilitou a abertura de uma ótica mais atenta para outras questões que permeiam a formação docente, em especial, a necessidade de considerar a subjetividade dos professores. Além disso, possibilitou a convivência com professores já em atuação, permitindo a troca de saberes entre os diversos participantes do projeto.

Por fim, destacamos a relevância de formações docentes que se proponham a uma formação para professores, muito além da perspectiva técnica ou teórica, permitindo olhar os professores como pessoas, inseridos em contextos concretos.

\section{Agradecimentos}

À Escola de Ensino Fundamental Elze Lima Verde Montenegro, por acolher o projeto, cedendo espaço físico e liberando os docentes para participarem das atividades formativas.

À Pró-Reitoria de Extensão da UECE, que nos apoiou na execução do projeto de extensão "Olhar para mim, para olhar para o outro, a dimensão subjetiva da formação docente".

\section{Contribuições de cada autor}

Os autores G.M.B.F. e A.V.F. escreveram o texto final; ambos os autores contribuíram com as análises dos dados; G.M.B.F. planejou e coordenou o projeto e A.V. F. atuou como bolsista.

\section{Referências}

Aguiar, W. M. J. (2006). Sentidos e significados do professor na perspectiva sócio-histórica: Relatos de pesquisa. São Paulo: Casa do Psicólogo.

Cunha, M. I. (1997). Conta-me agora: As narrativas como alternativas pedagógicas na pesquisa e no ensino. Revista da Faculdade de Educação, 23(1-2), 185-195.

Falcão, G. M. B, \& Farias, I. M. S. de. (2018). Narrativas de si constituindo docentes: Histórias de vida de professoras da educação básica. Cadernos de Pesquisa, 25(4), 167-184. 
Fernandes, M. R. (2000). Mudança e Inovação na pós-modernidade. Perspectivas curriculares. Porto: Porto Editora. Formosinho, J. (2009). Formação de Professores: Aprendizagem profissional e acção docente. Porto: Porto Editora.

Gatti, B. A. (1996). Os professores e suas identidades: O desvelamento da heterogeneidade. Cadernos de Pesquisa (São Paulo) 98: 85-90.

Gatti, B. A. (2008). Análise das políticas públicas para formação continuada no Brasil, na última década. Revista Brasileira de Educação 13(37), 57-70.

Gil, A. C. (2008). Métodos e técnicas de pesquisa social. 6ạ ed. São Paulo: Atlas.

Hargreaves, A. (1998). Os professores em tempo de mudança. Porto: Edições ASA.

Imbernón, F. (2010). Formação continuada de professores. Porto Alegre: Artmed Editora.

Minayo, M. C. de S. (2001). Pesquisa social: Teoria, método e criatividade. Petrópolis: Vozes.

Nóvoa, A. (1995). Profissão Professor. Porto: Porto Editora.

Nóvoa, A. (2009). Para uma formação de professores construída dentro da profissão. Revista de Educación, 350: 203218.

Pimenta, S. G., \& Anastasiou, L. das G. C. Docência do Ensino Superior. São Paulo: Cortez, 2002.

Silva, T. G. da. (2007). O processo de constituição da identidade docente: Vozes de professoras alfabetizadoras. (Dissertação de Mestrado). Teresina: Universidade Federal do Piauí - UFPI.

Vygotsky, V. A. (1994). Formação social da mente: O desenvolvimento dos processos psicológicos superiores. 3a ed. São Paulo: Martins Fontes.

Vygotsky, V. A. (2009). A construção do pensamento e da linguagem. São Paulo: Martins Fontes.

Como citar este artigo:

Falcão, G. M. B., \& Ferreira, A. V. (2020). A pessoa do professor: Significados e sentidos sobre uma experiência formativa. Revista Brasileira de Extensão Universitária, 11(2), 135-144. https://periodicos.uffs.edu.br/index.php/RBEU/ article/view/ 10859/pdf 